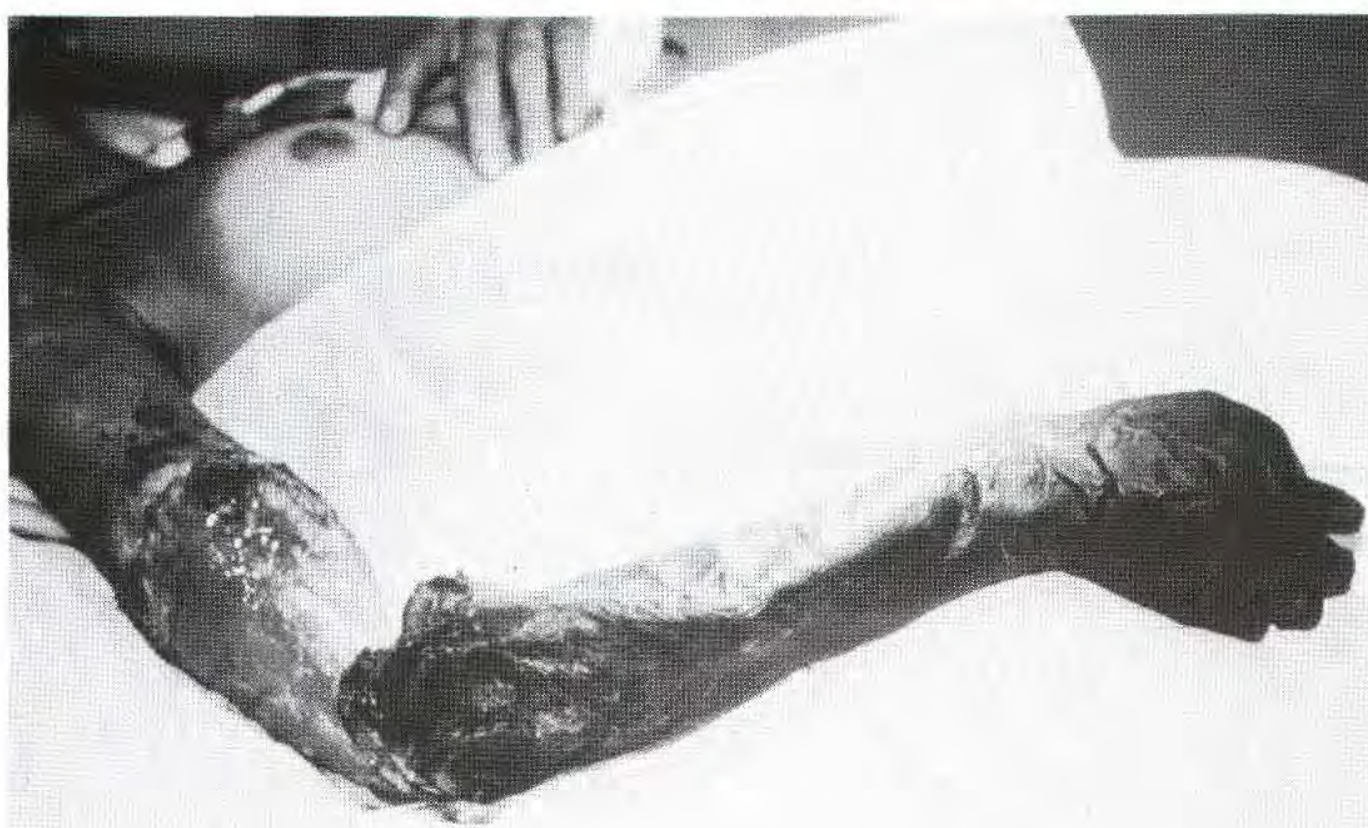

Fig 1. Case 2. Photograph shows dry gangrene of the right arm below the bandage.

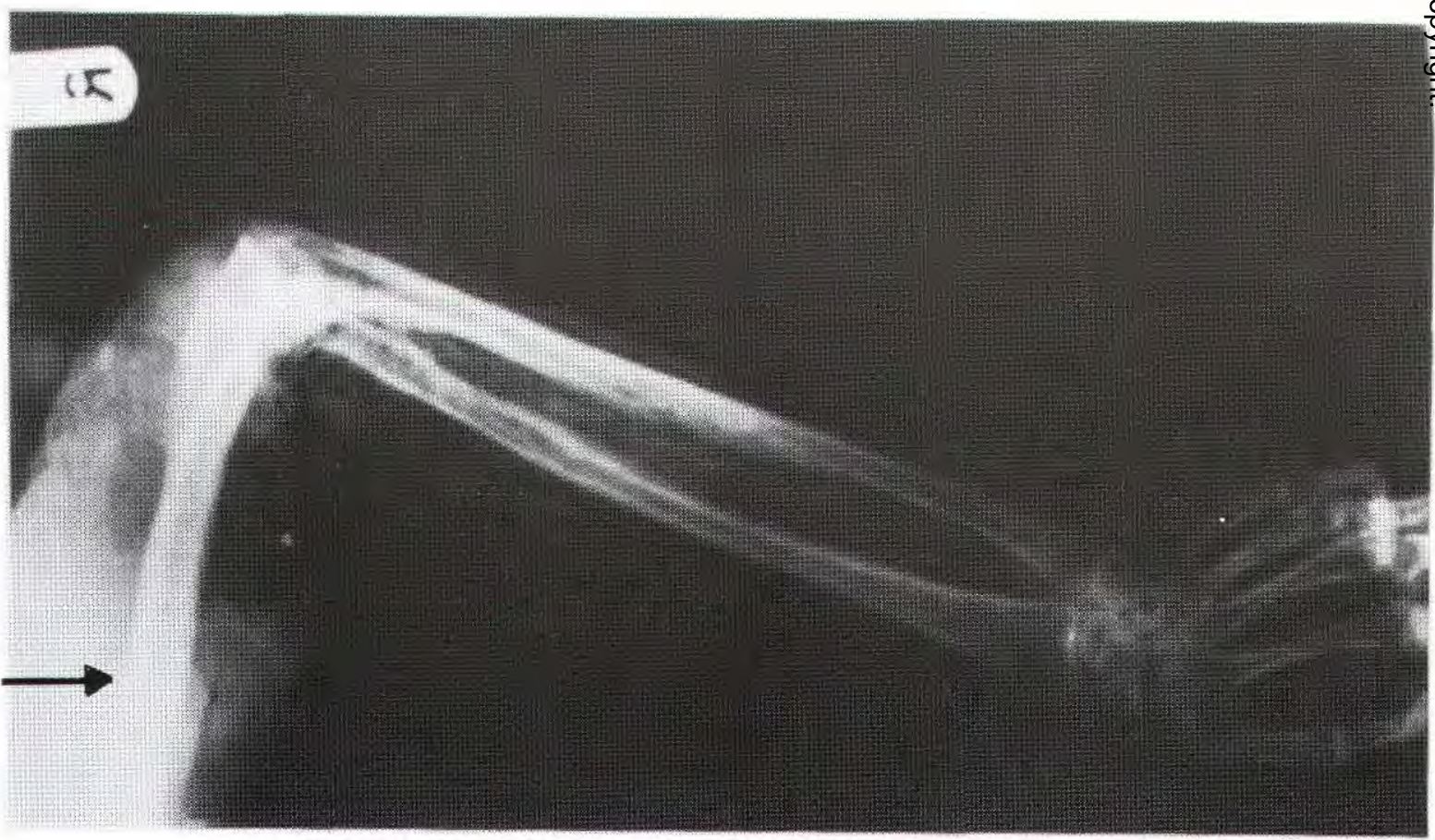

Fig 2. Case 2. X-ray showing fracture of the mid shaft of the right humerus. 


\title{
Inappropriate Traditional Treatment Resulting in Limb Amputation
}

\author{
Major N F Strowbridge, \\ $M B, B S, D A$, RAMC \\ Senior Specialist in Anaesthesia
}

Queen Elizabeth Military Hospital, Woolwich, London SE18

\author{
Lt Col J M Ryan \\ FRCS, RAMC \\ British Military Hospital, Dharan, Nepal, BFPO 4
}

SUMMARY: Four cases are described where inappropriate treatment by the traditional Nepali spiritualist healer or jhankri resulted in amputation of a previously healthy limb. Such treatments may involve the use of tourniquets, burning, scarification and herbal remedies.

\section{Introduction}

The British Military Hospital, Dharan, is situated at the base of the Himalayan foothills in South East Nepal. It treats not only Gurkha servicemen, pensioners and their dependants, but also a number of villagers and hillspeople who often have to trek for many days in order to reach Dharan.

There is a government programme to bring western style medicine to remote communities, but many still rely on traditional healers either through choice or necessity. The number of traditional healers has been estimated to be up to eight hundred thousand throughout Nepal, whilst the number of doctors working in the community is around five hundred ${ }^{1}$.

The effectiveness of these healers is unknown. In the past, many confined themselves to treating neurotic disorders and allied complaints with considerable success. However, a number of patients have presented to the British Military Hospital with complications following treatment of orthopaedic or surgical conditions.

The following cases illustrate how inappropriate treatment may lead to the amputation of a limb which would otherwise have healed with little or no intervention.

\section{Case 1}

A nine year old girl presented to the villagers' outpaticnt clinic having fallen from the porch of her house ten days previously, injuring her left arm. There was no soft tissue injury. The local jhankri was consulted and subsequently a tight tourniquet was applied proximal to the elbow joint. The arm was also scarified.

On examination the arm was gangrenous below the level of the tourniquet. There was a pyrexia of $38.5 \mathrm{C}$, but otherwise the patient was well.

It was decided that amputation was necessary and the girl was admitted. She was given benzyl penicillin, 1 million units every six hours. Full blood count revealed $\mathrm{Hb} 11.7 \mathrm{~g} / \mathrm{dl}$, and WBC $17.7 \times 10^{9} / \mathrm{l}(85 \%$ polymorphs,
$12 \%$ lymphocytes, $1 \%$ monocytes, and $2 \%$ eosinophils).

On arrival in theatre, anaesthesia was induced with thiopentone and maintained with nitrous oxide, oxygen and halothane. Closer examination of the limb showed a clear line of demarcation $2.5 \mathrm{cms}$ proximal to the medial epicondyle. Secondary infection was present almost to the axilla. An above-elbow amputation was performece and the skin flaps loosely tacked over a gauze-inos proflavin pack.

Formal closure took place, under general anaesthesia five days later. She made an uneventful recovery and was discharged on the 39th day. This delay was due $t ⿱ \bar{\Phi}$ difficulties in contacting the parents, who lived in the hills, and to the length of their trek to the hospital tr collect their daughter.

\section{Case 2}

This eighteen year old girl presented to the villagers clinic, having injured her right upper arm. She had fallen from a tree one month previously. The jhankri had been consulted and a tight bandage had been applied. This had been left in situ and had caused dry gangrene of the distal limb.

On examination, the arm was black and foul smelling and there was total loss of function (Fig 1). There was a mild pyrexia of $37.5 \mathrm{C}$. The patient was otherwise well. Radiography revealed a mid shaft fracture of the humerus (Fig 2). Full blood count showed $\mathrm{Hb} 11.2 \mathrm{~g} / \mathrm{d}$ l and WBC $6.6 . \times 10^{9} / 1(50 \%$ polymorphs and $45 \%$ lymphocytes). Serum urea and electrolytes and blood glucose were normal, as was the chest X-ray.

On arrival in theatre, a supraclavicular brachial plexus block was performed and the patient was lightly anaesthetised with halothane. A high above elbow amputation with lateral flaps was performed and the wound was packed with proflavin soaked gauze. Benzyl penicillin, 1 million units, was given every six hours. This was changed to oral penicillin the next day.

Formal closure took place three days later. The of patient made an uneventful recovery and was discharged $N$ on the twentieth day. 
Case 3

A nineteen year old Nepali male presented with a two month history of a painful right foot. He had originally fallen and the foot had become very painful, keeping him awake at night. There had been no breakage of the skin. The patient's parents had consulted the local healer who had burned the foot with a lamp. He had also applied herbal mixtures. The foot had rapidly become infected and gangrenous, and there was total loss of function. The family brought the patient to the clinic when he developed a high fever and became confused.

On examination the foot was black and foul smelling. The skin had peeled away in several areas, and this process extended proximally approximately $5 \mathrm{cms}$ above the ankle joint. The patient was confused with a pyrexia of $38.5^{\circ} \mathrm{C}$ and a tachycardia of $110 / \mathrm{min}$. Full blood count showed $\mathrm{Hb} 10.4 \mathrm{~g} / \mathrm{dl}$ and WBC $17.0 \times 10^{9} / 1(83 \%$ polymorphs and $17 \%$ lymphocytes).

On arrival in theatre, anaesthesia was induced with thiopentone and fentanyl, and maintained with halothane. A through knee amputation was performed, and the wound was closed loosely over a proflavin pack. He was given benzyl penicillin, 2 million units intravenously, and 1 million units intramuscularly every six hours therafter.

The wound was formally closed, under general anaesthesia, three days later. He made an uneventful recovery and was discharged on the fourteenth day.

\section{Case 4}

This young boy, aged eleven years, presented having fallen over at school some ten days earlier, and having injured his left forearm. He had been treated by a local healer who had bound the arm tightly with bandages.

On presentation there was gangrene of the hand and distal forearm. There was also a simple fracture of the radius and ulna. The patient was systemically well except for a mild pyrexia of $37.5^{\circ} \mathrm{C}$. Penicillin V $250 \mathrm{mg}$ six hourly was started. Full blood count revealed $\mathrm{Hb}$ $10.4 \mathrm{~g} / \mathrm{dl}$ and WBC $5.5 \times 10^{9} / 1(51 \%$ polymorphs, $41 \%$ lymphocytes, and $8 \%$ eosinophils).

He was taken to theatre on the following day. A supra-clavicular brachial plexus block was inserted, and the patient was lightly anaesthetised with halothane. Equal anterior and posterior myoplastic flaps were fashioned and an above elbow amputation was performed. The wound was packed with proflavin gauze.

Penicillin V was continued for eight days post operatively. Formal closure took place four days later. $\mathrm{He}$ was discharged home on the fourteenth day after an uneventful recovery.

\section{Surgical Management}

When they presented all these patients had dirty neglected wounds which were assumed to be heavily contaminated. They resembled wounds of war and were managed as such.
Initial treatment consisted of wound debridement and $\triangle$ amputation under antibiotic cover. Tetanus prophylaxis was not used. Human anti-tetanus globulin was available but only in small quantities, and was reserved for use in cases of established tetanus. Tetanus toxoid was considered inappropriate as our patients rarelyo return for follow up because some live ten to fourteenc days' walk from the hospital. Prevention of tetanus was achieved by good surgical technique together with high dose benzyl penicillin administered on arrival.

The upper limb amputations were performed at the믐 lowest possible level commensurate with the fashioning $\overline{\frac{5}{5}}$ of myoplastic flaps from clean viable tissue. Our one $\underset{\propto}{\mathbb{Q}}$ lower limb amputation was through the knee. Allo wounds were left open and dressed with proflavin gauze, $\stackrel{S}{\sim}$ wool and a crepe bandage. Patients were returned to? theatre on about day four for delayed primary closure. $\overrightarrow{\vec{\omega}}$ Our wounds healed uneventfully. All patients will beo considered for fitting of prosthesis if they can return for out-patient follow up.

\section{Discussion}

Many Nepalese villagers believe in the spiritual origin $\mathcal{C}^{\prime}$ of illness. Powerful invisible forces, if allowed to intrude $\frac{1}{\omega}$ uncontrolled into our visible world, may bring disorder of many kinds such as sickness, misfortune, disharmony. The traditional view of the jhankri is ofe of a spiritualist healer who, by virtue of his calling agd? training, has the ability to come into controlled contatio with these forces and negotiate their withdrawal. The을 are often ordinary people, like farmers and herdsmen, $\overrightarrow{0}$ who rarely devote their full time to this work, bot undertake it at night.

Although, to the western observer, the traditiona jhankri seems a mysterious figure, to those whom the treats he is a familiar one who knows both patient and family, and is willing to spend long hours in an effort to $\frac{\mathbb{D}}{2}$ isolate and identify whatever is causing the illness. Many such jhankris tend to confine themselves to oneō condition, often of neurotic origin.

Recent research, however, offers a different view. In the Kathmandu valley, Skultans ${ }^{1}$ has found that some Jhankris and other popular healers devoted their full time to this work, and saw many patients each day, while knowing next to nothing about their patients' back grounds or problems. No patients were turned away or referred elsewhere, and no illnesses were seen as falling outside their expertise. Many patients with acute physical and mental illness were dealt with. It would3 seem apparent, therefore from Skultan's work and from the cases that we have presented, that many spiritualist healers are no longer confining themselves to theiro traditional role.

The use of tourniquets in Nepal is normally confinedo to the treatment of snake bites. Fractures are usually treated by crude splinting. In three of the described 0 cases the over-zealous application of bandages, in order $N$ either to immobilise the limb or to keep herbal mixtures 
in place, may have had the same effect as a tourniquet.

Whatever the outcome of his treatment, the position of the traditional healer in the community is supreme in matters medical, and patients and their families are often loath to consult western doctors. In the case of the nine year old girl, for example, the eventual loss of the limb was blamed on our inability to cure the gangrene rather than on the initial tourniquet. The father stated that if he had foreseen the outcome, he would never have brought his daughter to hospital.

\section{REFERENCE}

1. Skultans V. Popular Healing in the Kathmandu Valley. Lancet 1986; i: 1025-26.

\section{Further suggested reading}

MiLler C J. Faith Healers in the Himalayas. Kathmandu: University Press, 1979.

Peters L. Ecstacy and Healing in Nepal. Malibu: Udena, 1981.

\section{BOOK REVIEWS}

Single Surgical Procedures - 36. Mucosal Proctectomy and Ileal Reservoir Formation. $T$ Vincent Taylor. Wolfe Medical Publications Ltd., 1986. Pp $4+63 . £ 14.00$. Illustrated.

The best way to study any surgical technique is to watch a master perform it, while listening to his simultaneous commentary. To reach a wider audience, in a more convenient form, Wolfe Medical Publications are producing a series - eventually to cover 200 titles where the master writes the commentary, and a series of high quality photographs illustrate each step.

This particular volume (No 36 in the series) is written by Mr.Vincent Taylor from Manchester, and describes mucosal proctectomy and ileal reservoir formation in the management of ulcerative colitis. The addition of the implied total colectomy presumably would have made the title too cumbersome.

The short introduction contains a good summary of the development of the surgical management of this condition, together with the author's indications for surgery both in general, and for this procedure in particular, and the all important, if obvious, contraindications to the latter. The short sections on pre- and post-operative management are eminently practical. Naturally, the bulk of the volume is devoted to the operative technique - over 100 photographs with mainly single sentence commentary on each.

It is appreciated that the publishers are aiming at completeness, and that surgeons of widely varying experience will peruse the volume. However, one wonders if the excellent photographs could not be reduced in number without overall loss of quality of the volume. Once particular vessels in the mesentary have been demonstrated, their division and ligation does not vary from that of similar vessels; four photographs to illustrate a standard abdominal closure seem irrelevant to the theme. A more general problem of the photographic demonstration of operative techniques is that in order to illustrate small details clearly, the field is so reduced as to impair overall orientation. The use of overprint identification, or complimentary simple line drawings might help overcome this common problem. That apart, the illustrations are of a uniformly high standard, and the commentary with each is precise and. succinct - although, as with the photography, occasionally repetitive.

The volume is well produced and for the number of colour photographs, reasonably priced. Surgeons of whatever experience who wish to acquaint themselves $\frac{\dot{s}}{\omega}$ with this procedure can do so conveniently by studyinge this volume - and it should therefore be available through their library. However, I doubt if many will wignt to buy their own individual copy.

Although not as valuable as standing beside $\stackrel{\mathscr{\infty}}{\mathrm{Mr}}$. Vincent Taylor while he performs a mucosil proctectomy, it is a very reasonable, and more practicint substitute.

M J PAYA

Single Surgical Procedures - 33. A Colour Atlas \&fơ Gastric Revision Operations. J Alexander Willian. Wolfe Medical Publications Ltd., 1986. Pp $7+$ $£ 14.00$. Illustrated.

This atlas is well produced and contains a large number of excellent photographs and illustrations, which show the procedure step by step very well indeed.

One must assume that it is intended for rank흘 beginners, as it was considered necessary to include photographs of general scenes in the scanning room and the operating theatre, the patient's abdomen being? prepared and draped, and even one showing the electrical lead being passed to the assistant. The reader is also advised that a right handed should stand on the patient's right, and the assistant on the left!

However, a surgeon who is likely to be doing a gastric revision operation should be fairly experienced and he would find the atlas superfluous. In spite of the title 3 suggesting otherwise, only one operation is included.

I would not agree that gastrostomy drainage of the stomach remnant after vagotomy and antrectomy is either necessary or that most patients would accept and welcome it however much they may abhor nasogastric intubation.

This in an unnecessary addition to the profusion of $\tilde{N}$ books and atlases already available in most libraries.

\section{N H PETERS}

